
Varia 



\title{
Estudios científicos y estética literaria. Un análisis del discurso médico-académico en la Argentina (1890-1910)
}

\author{
Pablo von Stecher
}

Hacia fines del siglo XIX, los conocimientos científicos que orientaron la investigación y la enseñanza médica en la Universidad de Buenos Aires trazaron un estrecho vínculo con el saber letrado. De la mano de médicos como José Ramos Mejía (1849-1914) o José Ingenieros (1877-1925), la referencia a distintas obras literarias irrumpió en géneros como lecciones, artículos y discursos catedráticos, y estimuló una formación integral del estudiante, que no se limitara a los intereses meramente clínicos. Asimismo, los cuadros patológicos de célebres personajes de ficción se constituyeron como un recurso didáctico para ejemplificar las explicaciones de enfermedades o degeneraciones estudiadas, principalmente, en las áreas de psiquiatría y criminología. Enmarcado en el estudio del discurso médico argentino del período 1890-1910, este artículo se propone analizar la conformación de un ethos culto y letrado, y los modos en que tal imagen fue proyectada para ser reproducida por el auditorio académico. El trabajo se inscribe en las tendencias francesas del Análisis del Discurso y apela a las referencias teórico-metodológicas de Ruth Amossy (Images de soi dans le discours..., L'argumentation dans le discours, "Nueva retórica y lingüística del discurso") y de Dominique Maingueneau ("Problèmes d'ethos", Doze conceitos em análise do discurso), concernientes a las categorías de ethos (discursivo y prediscursivo) y auditorio. El corpus de análisis está constituido por algunos enunciados producidos por Ramos Mejía e Ingenieros (tesis, lecciones, artículos médicos). Además, se consideran específicas publicaciones de la Revista del Centro de Estudiantes de Medicina (1901-1909) y de los Archivos de Psiquiatría y Criminología (1902-1914), dos revistas fundantes de la medicina argentina durante esta etapa.

PALABRAS ClaVe: ethos, auditorio, literatura, discurso médico, formación académica. 
At the end of the nineteenth century, the scientific knowledge that guided the research and medical teaching at the University of Buenos Aires forged a closed bond with the literary knowledge. The reference to different literary works, introduced by doctors as José Ramos Mejía (1849-1914) or José Ingenieros (1877-1925), appeared in genres such as lessons, papers and academic discourses, and encouraged an integral education of the student; a type of education that was not limited to clinical interests only. In addition, the pathological cases from famous fictional characters were constituted as a didactical resource in order to exemplify the explanations of diseases or degenerations studied, in the areas of psychiatry and criminology specially. This paper intends to analyze the conformation of a learned and "litterateur" ethos, within the frame of the Argentinian medical discourse that covers the period 1890-1910, and the ways in which this image was projected to be reproduced by the academic audience. The paper is involved with the French tendencies of Discourse Analysis and uses the theoretical-methodological references from Ruth Amossy (Images de soi dans le discours..., L'argumentation dans le discours, "Nueva retórica y lingüística del discurso") and Dominique Maingueneau ("Problèmes d'ethos", Doze conceitos em análise do discurso), concerning the categories of ethos (discursive and prediscursive) and audience. The corpus is composed of the same statements made by Ramos Mejía and Ingenieros (thesis, lessons, medical papers). In addition, specific publications of the Revista del Centro de Estudiantes de Medicina (1901-1909) and the Archivos de Psiquiatría y Criminología (1902-1914) - two foundational magazines of Argentinian medicine during these years - will be considered.

KEYWORDS: ethos, audience, literature, medical discourse, academic education.

Fecha de recepción: 2 de agosto de 2013

Fecha de aceptación: 30 de septiembre de 2013 
Pablo von Stecher

Universidad de Buenos Aires

\section{Estudios científicos y estética literaria. Un análisis del discurso médico-académico en la Argentina (1890-1910)}

\section{Introducción}

Hacia las últimas décadas del siglo XIX, la Argentina se vio asolada por una serie de epidemias que afectaron la sanidad poblacional. Como consecuencia de las masivas oleadas inmigratorias de origen europeo, proliferaron distintos brotes infecciosos (cólera, fiebre amarilla, peste bubónica, tuberculosis, sífilis) y se multiplicaron, particularmente, en las grandes ciudades del país, signadas por un defasaje entre el limitado desarrollo estructural y el caóticamente veloz crecimiento demográfico. En Buenos Aires, por ejemplo, el avance de tales enfermedades se veía favorecido por las crisis higiénicas y los problemas de hacinamiento y marginalidad urbana. En esta coyuntura surgía y se robustecía, asimismo, la criminalidad, considerada una patología "psicomoral" que amenazaba la salud social (Vezzetti, "La locura y el delito", 237; Vezzetti, La locura en la Argentina, 171-172).

Acorde a los intereses de sanidad y orden social manifestados por distintas instituciones estatales, la Facultad de Medicina asumió el desafío de dar respuesta a estos nuevos conflictos, y disciplinas como la Higiene, la Criminología y la Psiquiatría, se constituyeron como asignaturas privilegiadas en los planes de estudio de la carrera. Así pues, los estudios de figuras como José M. Ramos Mejía (1849-1914) y José 
Ingenieros (1877-1925), entre otros médicos e intelectuales argentinos, se propusieron actualizar los programas universitarios y los planes de estudio de la carrera de medicina.

Ahora bien, en este marco de renovación de teorías científicas, la enseñanza y la investigación de la medicina en la Argentina trazó un vínculo particular con el saber de las letras, relación todavía poco explorada por los estudios historiográficos y educacionales en el país. Enmarcado en el análisis del discurso médico argentino, este trabajo plantea el análisis de la construcción de un ethos médico culto y letrado, y los modos en que tal imagen fue proyectada para inspirar al estudiantado académico de la Universidad de Buenos Aires, entre las décadas de 1890 y 1910.

El artículo se propone constatar, por un lado, que en los distintos documentos de investigación y enseñanza médica de Ramos Mejía e Ingenieros, los casos de patologías propias de célebres personajes ficcionales provenientes del saber literario se conformaron como una herramienta privilegiada para la ilustración de explicaciones clínicas, y determinaron una alianza entre ciencias y letras que definió la construcción del ethos médico-académico del período. ${ }^{1}$ Tal construcción puede leerse, asimismo, a partir de una escritura atenta a ciertos recursos narrativos propios de la esfera literaria (léxico, estilo, descripciones) en la formulación de textos científicos. Por otro lado, expone cómo dicha imagen buscó ser incorporada y reproducida por el estudiante de medicina por medio de consejos y señalamientos dirigidos hacia el auditorio académico, pero también desde los conocimientos bajo los que este era formado. ${ }^{2}$

${ }^{1}$ Considerado, siguiendo a Ruth Amossy (L'argumentation dans le discours, 61), como "la imagen de sí mismo que construye el orador con su discurso". Tomo sus referencias teóricas (Amossy, Images de soi dans le discours..., L'argumentation dans le discours) y las de Dominque Maingueneau ("Problèmes d'ethos", Doze conceitos em análise do discurso) sobre la categoría de ethos (discursivo y prediscursivo) y tengo en cuenta sus consideraciones metodológicas en cuanto al relevamiento para tal análisis de la construcción del enunciador, y de los comentarios que éste efectúa sobre su propia enunciación.

${ }^{2}$ Construcciones recíprocamente tributarias, ethos y auditorio, el primero se conforma en función de lo que el orador considera que su auditorio sabe o espera de él. La categoría de auditorio permite, así pues, examinar la instancia en función de la cual el orador construye su discurso (Amossy, "Nueva retórica y lingüística del discurso", 5-6). 
El corpus de análisis se conforma por el "Discurso Pronunciado en el Círculo Médico" y las "Lecciones" de Ramos Mejía, trabajos compilados en el volumen Estudios clínicos de enfermedades nerviosas y mentales (1893); la tesis doctoral en medicina de José Ingenieros y su ensayo introductorio, La simulación de la locura (1900), La simulación en la lucha por la vida (1903), respectivamente; el artículo de investigación criminológica "Amor e incapacidad civil" (1909), producido por Ramos Mejía e Ingenieros, en coautoría. Asimismo, serán referidas específicas publicaciones de dos revistas médicas fundantes en el período. Por un lado, de la Revista del Centro de Estudiantes de Medicina, ${ }^{3}$ las "Cartas" (1909) que Héctor Taborda, su director, dedicó a los estudiantes-lectores. Por otro, de los Archivos de Psiquiatría y Criminología ${ }^{4}$ - publicación presidida por Ingenieros - el estudio sobre "La vida del delito y la prostitución. Impresiones médico-literarias" (1903) de Francisco Sicardi, otro renombrado médico argentino.

\section{Ramos Mejía y los parámetros del lenguaje médico}

Desde 1852, y durante casi veinte años, la Facultad de Medicina funcionó por fuera de la Universidad de Buenos Aires, debido al control del acceso a la comunidad profesional, buscado por la pequeña elite médica de entonces. Dos décadas después, un Ramos Mejía todavía estudiante encabezó una campaña por la renovación científica de los claustros. Como portavoz de un grupo de alumnos en ascenso, protagonizó la revuelta estudiantil del 13 de diciembre de 1871 (Veyga ,"Vida y trabajos del Dr. J. M. Ramos Mejía”, 14), empresa que cuestionó tal restricción a la participación en la comunidad académica y la imagen autocomplaciente de los catedráticos de la Facultad. Si bien la matrícula de Ramos

El auditorio fue abordado a partir de los índices de alocución (apelativos, formas pronominales). Por fuera del análisis enunciativo, desmonté los mecanismos de instalación de una exhaustiva serie de saberes culturales que, articulada a la enseñanza medicina, también ofrece elementos contundentes en lo que concierne a la conformación del ethos y del auditorio.

${ }^{3}$ Desde ahora RCEM.

${ }^{4}$ Desde ahora $A P C$. 
Mejía corría riesgos de ser negada, más afectado pareció verse el núcleo médico dirigente, perturbado por una crisis en su estructura interna que motivó el apartamiento voluntario de algunos catedráticos (González Leandri, “Académicos, doctores y aspirantes", 35; Buchbinder, Historia de las Universidades Argentinas, 51-53).

Tal revuelta tuvo su espacio de representación con la fundación del Círculo Médico Argentino en 1873, organismo creado por aquellos alumnos y jóvenes egresados. Desde el Círculo, dirigido por Ramos Mejía, se ejerció una fuerte presión para que la Facultad fuera reincorporada a la Universidad de Buenos Aires, y para que se renovara la estructura médica. A partir de entonces la carrera académica de Ramos Mejía se aceleraría de modo inusitado, de la misma manera en que avanzaría su trayectoria institucional en las décadas siguientes. Así pues, se desempeñó al frente de la Cátedra de Enfermedades Nerviosas desde 1888 (año de inauguración de la materia) hasta 1914 (Ingenieros, La locura en la Argentina, 49-51). También presidió el Departamento Nacional de Higiene desde 1892. En la primera década del siglo Xx, Ramos Mejía volcó su atención hacia la formación escolar en el país y, desde 1908, ejerció la presidencia del Consejo Nacional de Educación y coordinó su publicación oficial, El monitor de la Educación Común.

En su "Discurso ante el Círculo Médico” (1891), Ramos Mejía afirma:

Ah! señores, no quisiera pasar esta oportunidad sin decir dos palabras sobre una perjudicial preocupación que domina a nuestros médicos, ya que con este motivo traigo a vuestros oídos el nombre respetable de Renan, el más grande e irreprochable escritor de su tiempo. Se ha creído siempre entre nosotros, y los viejos maestros nuestros se han encargado de transmitirlo como animados por un santo horror ortodoxo, que el perfecto médico debía ignorar por completo las más rudimentales nociones de la educación literaria; que para ejercer con éxito este noble arte que ejercemos era menester que desconociéramos los más bellos productos del espíritu de esa amable y atrayente rama de los conocimientos humanos indispensables, y que el clínico perfecto debía apenas saber coordinar dos malas ideas sobre el papel. Error, señores, error funesto para la educación superior que recibíamos. En ese tiempo, y no creáis que exagero, porque todavía hay entre nosotros ejemplares de adeptos empecinados 
de esa escuela; en esa época, decía, llamar literato a un estudiante equivalía a la clasificación de hereje y judaizante en los buenos tiempos de Arbues y Torquemada. Yo fui una de sus víctimas, porque cuando por razones que no ignoráis, quisieron levantarme un proceso público por haber empleado mi literatura en beneficio de aquella vieja y venerable institución, dijeron, en descargo de sus conciencias meticulosas, que yo era un estudiante literato, un escritor, como si dijéramos una pequeña furia del Averno o un candidato al ostracismo de la ciencia. Non erat dignus entrare in illo docto corpore, como decía graciosamente ese inolvidable medicastro que ha inmortalizado el genio de Moliére (44).

Mediante la interjección, el apelativo como índice de alocución y la referencia a las "dos palabras" que el locutor precisa establecer, introduce la cuestión de la cultura literaria en la formación clínica y convoca la atención de su auditorio ante esta inquietud. Tal preocupación parte de un discurso proferido desde el pasado por "los viejos maestros", pero continúa aún en la formación presente de otros "ejemplares adeptos empecinados de esa escuela", concerniente a la imposibilidad de articular el saber médico con el saber letrado. Superar la aberración que suponía la autoexclusión de los conocimientos en pos de uno integral, al contrario, favoreció la empresa de renovación académica emprendida por el locutor. Articulado a un enunciador en primera persona, apela a su experiencia personal en tanto estudiante amenazado por la institución - o victimizado por la Inquisición - para demostrar, dado el estatuto desde el que se pronuncia en la actualidad enunciativa (Presidente del Círculo Médico, Jefe de Cátedra de Enfermedades Nerviosas), que esa advertencia ante sus conocimientos y virtudes literarias no fue sino un error. Al señalar que las razones del proceso público que marcaron su paso juvenil por la universidad es un dato "que no ignoráis", éstas se confirman como una referencia extradiscursiva ya conocida por el vosotros-destinatario en la conformación del ethos previo. ${ }^{5}$

El locutor enfatiza, de este modo, la denuncia sobre "los médicos que creen que el saber expresar con buenas formas sus ideas establece

${ }^{5}$ El ethos previo, entiende Amossy, puede indagarse en las dimensiones extraverbales del orador, las que incluyen tanto niveles sociales-institucionales (renombre, reputación, estatus, prestigio) como niveles morales (cualidades, personalidad, modos de vida) (L'argumentation dans le discours, 71). 
incompatibilidades con la clínica", al contrario, advierte que "la regla de buen estilo científico, es la claridad", por lo que al explicar, el médico debe evitar "el desorden, la obscuridad, la incorrección" (46). Al frente del Círculo, y en posición de pedagogo, el locutor enfatiza las ventajas que ofrece el hábito de la lectura, como requisito para la buena expresión de las ideas. La producción de discursos médicos eficaces, entonces, no dependerá únicamente de los contenidos difundidos, sino que el estilo preciso y la estructura organizada a partir del cual estos se pronuncien operará a favor de una sólida formulación y de una precisa exposición del pensamiento.

La interpelación al auditorio hacia la lectura como herramienta de una eficaz difusión de enunciados, culmina en la apelación a un serie de ejemplos por autoridad: "los grandes maestros son grandes escritores, como Bernard, Charcot, Trousseau, Duchenne [...] eminentes artífices del lenguaje encerrando dentro de su estilo grande, sólido y elegante, su pensamiento fuerte" (46). Los referentes franceses de las distintas especialidades de la medicina moderna son entonces recuperados como prototipos de esta exitosa imbricación entre el saber clínico y el saber oratorio. En efecto, la precisión no es la única virtud que se difunde como necesaria del estilo, sino que éste también debe ser "sólido y elegante", atributos que sólo se alcanzan mediante la práctica de la lectura.

\section{El mensaje de las letras en el Centro de Estudiantes de Medicina}

La incidencia de Ramos Mejía en la redacción de la Revista del Centro de Estudiantes de Medicina de la Universidad de Buenos Aires no debe ser desestimada. Por un lado, su figura se presentó como modelo a seguir en las nuevas luchas de los estudiantes por las reformas universitarias en medicina hacia $1905 .{ }^{6}$ Por otro lado, Ramos Mejía formaba parte

\footnotetext{
${ }^{6}$ Durante este año se llevó a cabo una huelga estudiantil como modo de protesta ante la indiferencia de la Comisión Directiva de la Facultad de Medicina por los reclamos de reformas administrativo-académicas. La RCEM se constituyó como órgano portavoz y propulsor en la participación de todos los estudiantes en la huelga ( $C f r . ~ R C E M$ núm. 50, 353-356; núm. 56, 388-389; 390).
} 
de la dirigencia en la Liga Patriótica, ${ }^{7}$ asociación que promovía una serie de actividades de deportes, tiro, y competitividad física entre los estudiantes de medicina, y cuya difusión ocupaba parte importante entre las secciones de la RCEM. De hecho, cuando el Centro de Estudiantes obtuvo los primeros logros certeros de su proyecto reformista en 1906, la $R C E M$ publicó una nota de felicitación escrita por la Junta Ejecutiva de la Liga Patriótica que aplaudió su actitud "valiente y patriótica" (RCEM núm. $56,398)$. En la medida en que la Liga entendía estos cambios como un paso adelante en el "progreso científico de nuestro claustro Universitario" (399), se mostró plenamente interesada en apoyar la campaña de reformas. De frecuencia mensual, la RCEM fue publicada desde septiembre de 1901, un año después de la fundación del Centro, hasta junio de 1909, momento en el que se produjo la unión del Centro de Estudiantes de Medicina con el antiguo Círculo Médico Argentino, y en el que surgió una nueva revista, cuyo título aunaba las denominaciones de ambas agrupaciones.

Si bien la RCEM publicó distintas notas culturales desde su surgimiento, no fue sino bajo la dirección del estudiante Héctor Taborda ${ }^{8}$ - que asumió el puesto de responsable principal, con el número 83 en $1908-$ que el interés por la difusión de la literatura se constituyó en uno de los ejes primordiales. En dos cartas (una inaugural en su cargo de director y otra que anunciaba el final de la publicación) que Taborda dirigió a sus

${ }^{7}$ Se trata de la asociación fundada en 1898 con el fin de estimular y vigilar cualquier instancia relacionada con la inminente situación de guerra con Chile. La Liga tendió a crear una red de propaganda patriótica integrada por las filiales que fundaba en cada una de las ciudades y pueblos de la República. Su mensaje se centró en el abandono del pacifismo, la incitación a prepararse para el combate y la firme unión de toda la población en defensa de la patria (Bertoni, "Soldados, gimnastas y escolares", 53-54). En este sentido, al tiempo que la RCEM gozaba del apoyo de la Liga Patriótica, el Tiro Federal y la Guardia Nacional, difundía los torneos de tiro y deportes que estas asociaciones incitaban con el fin de tener una población joven alistada para el deber bélico. En los siguientes números de la RCEM se puede rastrear la propaganda sobre el deber patriótico y deportivo que se intentó inculcar sobre los estudiantes de medicina: RCEM núm. 11, 317; núm. 12, 349; núm. 14, 427; núm. 56, 431-433.

${ }^{8}$ Héctor Taborda fue un estudiante paradigmático en tanto representante de la Universidad de Buenos Aires en distintos congresos latinoamericanos que trataron la problemática sobre la reforma universitaria (Biagini, "Redes estudiantiles en el Cono Sur (1900-1925)", 84). En el marco de la Facultad de Medicina fue adscripto de José Ingenieros, cuando éste ocupaba el puesto de Director en el Instituto de Criminología. 
lectores, propuso las definiciones de la $R C E M$, de sus propósitos, y de la formación del estudiante de medicina. La revista debía ser entonces:

[...] la expresión de diversas modalidades intelectuales [...] Importantes innovaciones se han hecho en lo que al material se refiere, dando cabida en sus columnas a producciones que, saliendo del campo puramente científico, ofrecen un particular interés al intelectual a la vez que fomentan, entre los estudiantes, la cultura de las letras [...] El caso clínico y los apuntes de las asignaturas ya no son, o no deberían ser, suficientes [...] Por el hecho de ser estudiantes de medicina, no deja cada uno de nosotros de seguir el camino de otras particulares aficiones intelectuales ("Carta a mis lectores", 1-2).

La $R C E M$ era también:

[...] el trasunto constante de la intelectualidad del gremio estudiantil de medicina, pero con miras más amplias, de manera tal que en ella se reflejen todas las formas activas de esa intelectualidad [...] Al lado del trabajo experimental o clínico, debe ir como otra manifestación mental, el trabajo de abstracción, el comentario doctrinal, la nota psicológica o sociológica, la contribución artística o jocosa, aunando así en natural consorcio lo útil y lo agradable ("Carta de despedida", 1-2).

De este modo, Taborda recupera el mensaje de Ramos Mejía que convocaba a la necesidad de ampliar los conocimientos del alumnado, así como al beneficioso desarrollo intelectual como resultado de una instrucción integral de saberes. La importancia por esta profusión de nuevos objetos que amplía las secciones de la RCEM es articulada como un imperativo en ambas cartas. En orden a estos propósitos, el número 88 de la RCEM publica las estrofas de La Maison Ideale 9 (310-311) - en lengua original - del poeta francés Xavier Privas (1863-1927); y al año siguiente edita, en el número 93, el poema Le prodige (250) del escritor y político parisino Pons de Verdun (1759-1844).

${ }^{9}$ La poesía, que describe justamente como debería ser una casa de estudios perfecta para los alumnos, colmada de esfuerzo y trabajo, pero también de alegría, esperanza y orgullo, ilustra los informes de avances en torno a la construcción de una residencia estudiantil, bajo un proyecto de ley elaborado por el célebre educador y político argentino, Joaquín V. González. 
En su último número, en tanto, la RCEM presenta, "El manuscrito de un médico de aldea" (núm. 94, 92-100), cuento de Anatole France (1844-1924). ${ }^{10}$ Publicado en español y extendido a lo largo de ocho páginas de la revista, el relato reconstruye el diario de un médico rural de Francia, en el que la enfermedad es configurada como un desafío a afrontar y el médico como un observador objetivo de la naturaleza. Justamente cuando el científico permite que la dimensión afectiva interfiera en su trabajo, comienzan los errores: olvida lo que medicó, necesita una segunda opinión y, finalmente, su paciente muere. En este sentido, la coyuntura científico-naturalista del cuento introduce a los futuros médicos en el mundo de ficción, pero a partir de una situación y de un objeto que pertenece a su campo. Asimismo, les ofrece la posibilidad de reflexionar sobre su propia actividad, a través de un punto de partida originado en otro campo del saber.

A partir de la publicación de estos textos literarios, entre otros, ${ }^{11}$ la RCEM, de la mano de Taborda, también asumió el desafío de despertar entre los alumnos el interés por este tipo de "modalidades intelectuales" capaces de articular ciencias y letras, manifestaciones respectivas de los valores de "lo útil" con "lo agradable". No obstante, a diferencia de este enfoque, veremos que desde las perspectivas de Ingenieros y Ramos Mejía, la literatura también ocupará el valor de lo propiamente "útil" en el desarrollo del estudio médico.

${ }^{10}$ Sin duda, fue la literatura francesa la que más interés generó entre los redactores de la $R C E M$. Además de las referencias señaladas, en el primer número en que la $R C E M$ se une a la Revista del Círculo Médico, se traduce y analiza una cita de Víctor Hugo ( $R C E M$ \& $R C M$ núm. 1,33). José Luis Romero ha señalado el modo en que la sabia ironía de Anatole France, así como su escepticismo y su interés por los misterios del espíritu que superaban las experiencias cognoscitivas de las ciencias, se instaló con fuerza en la profunda renovación estética que vivió Buenos Aires hacia los últimos años del siglo XIX (El desarrollo de las ideas en la sociedad argentina del siglo xx, 91-92).

${ }^{11}$ Asimismo, se publicó una reflexión del médico argentino Osvaldo Loudet sobre "La moral de la ciencia", en la que se analizan una serie de referencias de Víctor Hugo concernientes a la lectura del universo a partir de las verdades que ofrece la ciencia ( RCEM \& RCM núm. 1: 33). El homenaje al médico y escritor argentino, Francisco Sicardi, también tuvo lugar en este número de la publicación. Nos referiremos al mismo en el apartado de Los médicos literatos. 
La literatura como inspiración para la ciencia. Un recorrido por la biblioteca de José Ingenieros

En la construcción de un ethos culto e ilustrado que se empieza a elaborar en el "Discurso ante el Círculo Médico" de Ramos Mejía, y que tiene también su correlato en el marco de las lecciones de neurología publicadas en el mismo volumen (Estudios clínicos de enfermedades nerviosas y mentales, 1893), el saber literario se establece como un elemento recurrente. La alusión a los tristes círculos del infierno del Dante, para sancionar moralmente a los alcohólicos delirantes en la "Lección vi: Los toxicómanos o bebedores de veneno" (176), o la indicación sobre el "amor neurasténico y desequilibrado de Madame Bovary" en la "Lección v: Los epilépticos bromiómanos", son otras referencias que, en vinculación a la cita en latín atribuida al personaje de Moliere (44) desplegada en el discurso ante el Círculo (ver "sección 1"), habilitan la configuración de dicha imagen letrada.

No obstante, ha sido José Ingenieros, alumno de Ramos Mejía en la clase de 1898, quien sin duda supo articular su exhaustivo saber literario en el desarrollo de sus apuntes psiquiátrico-criminológicos. Ingenieros se recibió de médico en 1900 y se desempeñó como Director del Servicio de Observación de Alienados hacia 1904, y como Director del Instituto de Criminología de la Penitenciaría Nacional desde su fundación en 1907 (Ponce, "Para una historia de Ingenieros", 33; Rovaletti, "Panorama psicológico", 300).

Los enunciados que dan inicio a La simulación en la lucha por la vida, el ensayo introductorio de su tesis doctoral, proponen la descripción de una escena cotidiana y autorreferencial: Ingenieros sumergido en la lectura del mismo autor que algunos años antes citaba su maestro:

De sobre el velador tomamos, una noche, el Malade imaginaire de Moliere, para continuar su comenzada lectura, con el higiénico propósito, entre otros, de no adormecernos bajo la influencia poco grata de una monografía sobre Nuevos tratamientos de los bolos fecales [...] Las peripecias de Argan prolongaban nuestra vigilia más allá de los límites habituales (10).

En este marco se construye la hipótesis preponderante en su teoría de la simulación, aquella que vinculaba los recursos de mimetismo de los 
animales en la lucha por su supervivencia, con las estrategias de simulación de patologías psiquiátricas en criminales, en su intento por evadir la pena judicial. La alternancia entre la lectura de "las operaciones científicas de los médicos de Moliere" y las reflexiones sobre los delirantes apócrifos, en conjunto con la visión en su pared de aquel insecto "camuflado" bajo un copo de algodón para evitar ser descubierto, se establecen como las fuentes de inspiración que le permiten a Ingenieros construir su hipótesis. "Hubiéramos continuado la lectura de Moliere; pero en nuestro cerebro estaban sometidas a la elaboración de la cerebración inconsciente múltiples cuestiones relativas a los alienados criminales, y, de manera especial, a los delincuentes simuladores de una enfermedad mental" (12). La obra maestra de Moliere, al contrario de la monografía médica irónicamente referida, se presenta entonces como la instancia de inspiración en la construcción de una de las ideas determinantes en el avance de la tesis de Ingenieros.

A partir de entonces, y con el fin de instalar y explicar las distintas dimensiones del fenómeno de la simulación se recurre, en la introducción a la tesis, a múltiples ejemplos de la literatura universal: un poema de Goethe, para referir a la astucia del zorro simulador (54), la Fisiología del matrimonio de Balzac, para señalar la simulación en la vida conyugal (70), la obra de Quevedo, para describir la simulación en la comunidad médica (71). Asimismo, con el propósito de ilustrar al arquetipo del simulador-criminal propio de las grandes urbes, se mencionan "el Shylock, de Shakespeare; el Robert Macaire, de Lemaitre; el Mercadet, de Balzac; el Saccard, de Zola" (82). Desde esta perspectiva, que se desarrolla a partir de las representaciones literarias como andamiaje descriptivo de las problemáticas psicológicas y médicas, se enumera:

Los tipos creados de Shakespeare a Ibsen, de Cervantes a Zola, de Calderón a Dostoiewsky, serán eternos modelos psicológicos de caracteres humanos empíricamente observados; los mejores trabajos debidos al método científico podrán igualar, mas no superar, a un tipo de Macbeth o Stockmann, Sancho o Saccard, Segismundo o Raskolnikoff (90).

Así pues, las complejas afecciones y los profundos padecimientos de los distintos personajes de ficción, configurados a partir de la pretensión estética y de las estrategias descriptivas y narrativas de la literatura, 
resultan ejemplos tan enriquecidos que permiten ilustrar, tal vez mejor que cualquier otro registro, el saber científico. En el mismo sentido, proliferan las reminiscencias a la literatura gauchesca nacional, por un lado, el Juan Moreira de los folletines de Gutiérrez es presentado como un "tipo psicológico especial", anclado en su carácter temerario (104); en tanto que las referencias a los consejos del Viejo Vizcacha - célebre personaje del poema gauchesco argentino por antonomasia, el Martín Fierro de José Hernández - en cuanto a desconfiar de la victimización y el sentimentalismo de la mujer son esbozados como saber popular que confirma la predisposición a la simulación en la psicología femenina (115). Tampoco son escasas las reminiscencias a los clásicos griegos y latinos, las obras de Plutarco, Tito Livio y Ovidio, entre otras, son recuperadas para ilustrar la problemática concerniente a la simulación de la locura (12-14). La conjugación de todo este dispositivo literario que se despliega a partir de múltiples exponentes en las diferentes etapas de las letras universales, ${ }^{12}$ articulado en aproximaciones, comparaciones, analogías y referencias recíprocas, deja de manifiesto la operatividad de esta rama de la erudición en la construcción del conocimiento científico.

\section{La cultura letrada en los Archivos de José Ingenieros}

Tal como su título lo indica, la empresa editorial que Ingenieros asumió en 1902 con la dirección de los Archivos de Psiquiatría y Criminología aplicados a las Ciencias Afines: la Sociología, el Derecho, la Psicología o la Pedagogía $(A P C)$, tuvo como interés particular la exposición y difusión de contenidos que no se limitaran al mero caso psiquiátrico o criminológico, sino a un saber transdisciplinar en el que aquellos conocimientos convergieran. Además de comprender "Artículos Originales", "Observaciones clínicas” y "Reseñas de Revistas", ${ }^{13}$ la publicación

${ }^{12}$ Además de retomar ilustraciones provenientes de los clásicos de la Antigüiedad, así como de los afamados autores de la Edad Media y del Renacimiento, Ingenieros remite a los grandes poetas simbolistas franceses, como Baudelaire y Verlaine, para ejemplificar, no ya a partir de sus obras sino de su biografía, casos clínicos de "enfermizos del arte" que "lindan con el delirio de las grandezas o la erotomanía" (141).

${ }^{13}$ No sólo se realizaban reseñas de publicaciones médicas nacionales e internacionales, sino que también se exponían en esta sección revistas como Filosofía y Letras o 
ofrecía las secciones de "Variedades Científicas" y "Notas", en las que se comentaban distintas elaboraciones culturales que se vinculaban al quehacer médico y en las que la reflexión literaria ocupaba un espacio privilegiado.

\section{El diagnóstico del personaje literario como ejemplo de la exposición psiquiátrica}

La operación efectuada por Ingenieros y Ramos Mejía, basada en la articulación del material literario en el desarrollo del estudio científico se inscribe en una tradición europea que había empleado este recurso para el desarrollo de los estudios psiquiátricos y médico-legales. ${ }^{14}$ En este sentido, los $A P C$ exhiben una sinopsis del informe sobre "Los Degenerados y Criminales en la obra de Zola" del criminólogo italiano Enrique Ferri e introducido por Ingenieros (APC vol. I, 622-670), y una investigación sobre "La locura de Don Quijote" del psiquiatra español y Director de la Revista Fernopática Española, Antonio Rodríguez-Morini (18631937), (APC vol. v, 763-767), en 1902 y 1906, respectivamente.

En el primer caso, Ingenieros refiere que Ferri fue sólo uno de los "muchos psicólogos y criminalistas" que, capaz de ver al sociólogo de-

Revista de Derecho, Historia y Letras (APC vol. I, 764). Graciela Salto ("De las escenas de colegio a las escenas de hospital", 113) se ha referido al modo en que el avance de los médicos sobre otras esferas de la actividad cultural y social, había implicado también una ampliación del espectro de su inserción institucional: entidades como el Centro Científico Literario, el Círculo Científico y Literario, el Instituto Frenopático o la Academia Argentina de Ciencias y Letras eran formaciones culturales que, en las dos últimas décadas del siglo XIX, aglutinaban el interés por las ciencias y la intensa actividad literaria de la mayor parte de sus miembros.

${ }^{14}$ En su artículo sobre "La psicología en el arte" (27-40), Ingenieros refiere: "La crítica médico-psicológica, aplicada al análisis de los tipos presentados en las obras de arte, tiene ya luminosos precedentes que la explican y justifican. Charcot y Richet estudiaron los demoníacos en el arte. Ferri y Alimena tomaron a algunos personajes de Shakespeare, Zola, Bourget, D’Annunzio, Ibsen, Tolstoy, Dostoyewsky. Lombroso paseó su mirada psiquiátrica por las almas que mueven en "Germinal" de Zola. Lefort escudriñó la psicología íntima de los personajes representados en las grandes telas clásicas. Niceforo analizó los degenerados y criminales del infierno dantesco. Debove disecó, en su ironismo sublime, los personajes sobresalientes de Moliere" (27). 
trás del novelista, abordó la obra de Zola bajo el enfoque de una "disecación de la sociedad" y "una profecía sobre los vicios y las miserias de la presente organización" (622). En el segundo caso, Rodríguez Morini reconoce que Cervantes ha creado "el tipo más admirable de vesánico que pudiera apetecer como caso clínico el alienista más exigente" (763) y considera que así como la lectura del Quijote ha suscitado inagotables y magníficas reflexiones provenientes de disciplinas como la Gramática, la Historia, la Crítica y la Retórica, un papel similar debe ocurrir con las intervenciones proyectadas desde la Medicina Psicológica (764).

La elaboración de Rodríguez Morini, en particular, dialoga de manera continua con el estudio Primores del Don Quijote en el concepto médico-psicológico (1886) del reconocido médico psiquiatra español Emilio Pi y Molist (1824-1892), también publicado en los APC (vol. XI, 611-616). Pi y Molist afirmaba que la enfermedad del personaje estaba de acuerdo con los conceptos de la monomanía, admitidos por la medicina mental de entonces. ${ }^{15}$ En este sentido, la aceptación general que ofrecía este recurso interdisciplinar como aval para la reflexión científico-cultural no resultaba desconocida para los médicos argentinos que leían y publicaban en los APC.

En efecto, una de las consideraciones que sostuvo Ingenieros en su tesis, y por lo que combatió contra las anacrónicas leyes criminológicas argentinas del período, fue la que sostenía los criterios de responsabilidad legal del delincuente y de irresponsabilidad del alienado. A modo de sustentación de esta propuesta y una vez analizadas las observaciones médicas en su tesis doctoral, La simulación de la locura (1900), Ingenieros concluye el capítulo tres con el apartado "Una página del Quijote". En esta, se describe el episodio en que el hidalgo hiere a los herreros que alteran su ceremonia de veneración de armas en la venta y recibe un posterior ataque por parte de aquellos. Ante esta situación, el ventero, "conocedor de la locura del Quijote", lo defiende y ordena el cese del ataque ante los herreros. La tesis, finalmente, refiere:

${ }^{15}$ La obra, editada en la Imprenta Barcelonesa en 1886, compila una serie de artículos ("Antecedentes necesarios: apuntes de medicina", "Epifenómeno de la locura de Don Quijote", "Cordura subsistente en la locura", "Metamorfosis de forma de la locura", "Curación de Don Quijote", "Locos simpáticos") que debaten sobre los conflictivos límites de la locura y la cordura en torno al cuadro psiquiátrico del personaje literario. 
[...] el ventero sabía ya, por entonces, que la locura es una causa eximente de pena, anticipándose a las sanciones que los códigos penales establecieron muchísimo tiempo después. Tras este breve paréntesis, que nos muestra el arte interpretando con felicidad el criterio jurídico de la irresponsabilidad del delincuente alienado, podemos sintetizar en breves conclusiones las bases jurídicas de la simulación de la locura por delincuentes (119).

De este modo, aunque la referencia sea presentada como una digresión del orador, su operatividad en el marco de la argumentación supera su articulación como comentario que destaque la imagen culta de aquél, para establecerse como un último fundamento que, previo a las conclusiones, termina de sostener su punto de vista. La incuestionabilidad del ejemplo-argumento que establece la irresponsabilidad del alienado se sostiene también en términos temporales. Por extensión del personaje al autor se señala que "Cervantes tenía ya clara noción de ello [la irresponsabilidad del alienado]" (118), por lo que la repetición del adverbio temporal ("el ventero ya sabía") enfatiza que el conocimiento de este dato puede ser confirmado desde un pasado remoto.

Otro ejemplo de esta concepción en la construcción del conocimiento científico, que tiene lugar en la misma tesis de Ingenieros, puede leerse a partir del modo en que se recupera una estrofa de La vuelta de Martín Fierro (1879) como un antecedente que alude a la propensión simuladora de la locura como rasgo propio de los inmigrantes italianos arribados al país. En este caso, el hijo de Martín Fierro narra sus desventuras y desamparos desde la Penitenciaría y refiere cómo tales inmigrantes resultan "sujetos peligrosos", entre los perturbadores del orden público, en tanto cuentan con una lengua extraña que opera como instrumento propicio para la simulación y el engaño frente a las instituciones médicas y jurídico-penales:

Todos los que han leído el popular poema criollo, Martín Fierro, recordarán aquellos versos en que se alude a la simulación de la locura: Criollo que cae en desgracia / tiene que sufrir un poco; / nadie le ampara tampoco, / si no cuenta con recurso. I El gringo es de más discurso: I cuando mata se hace el loco (103). ${ }^{16}$

${ }^{16} \mathrm{Si}$ bien el diccionario de la $R A E$ define al gringo como el extranjero, especialmente de lengua inglesa (1158), debe distinguirse el modo en que en Centroamérica y en 
En un sentido similar, la investigación sobre "Patología de las Funciones Psicosexuales" que Ingenieros publica en el volumen IX de los APC (3-80) señala el cuadro de las Hiperafrodisias instintivas, patología caracterizada por un instinto sexual exagerado, independiente de toda exaltación genital y/o emocional. No es sino "la literatura de todos los tiempos y de todos los países [que] ha representado el tipo de "Don Juan" (19), la ilustración más precisa, y asumida como conocida para los lectores, que pueda ejemplificar los parámetros que ofrecen la explicación de esta disfunción psicosexual.

De este modo, los cuadros clínicos y los síntomas de distintos personajes literarios son incorporados como un recurso, ya instalado en las reflexiones científicas europeas, para ilustrar el desarrollo argumental de una tesis doctoral en medicina y de otros géneros académicos. Y, en algunos casos, su inclusión opera como fundamento por referencia a una autoridad de la cultura letrada, aún en el marco de una fundamentación científica, en su especialidad médico-legal.

\section{La pasión como enfermedad. Abordajes científicos y filosóficos}

En su investigación dedicada al "Amor e incapacidad civil", ${ }_{17}^{17}$ Ramos Mejía e Ingenieros analizan en términos legales y en términos psiquiátricos la pasión amorosa de X. N., de 20 años, hacia una mujer "casada y hermosa", y la posterior denuncia efectuada por el padre del joven, al conocer la situación. Entienden que sólo si esa pasión llevara a actos vedados por la moral y la ley sería condenable, al contrario, de acuerdo al modo en que se desarrolla el caso, "absurdo sería que la ley civil incapacitara al enamorado" (APC vol. VIII, 543), así como tampoco sería posible considerar la pasión amorosa - fase propia del proceso psi-

ciertos países de América del Sur como Ecuador, Venezuela y Paraguay se lo aplicó al norteamericano, en cambio, en la Argentina debido al importante caudal de inmigrantes italianos, se lo asoció a los llegados de ese país. Para Cibotti ("Del habitante al ciudadano", 373), epítetos como el de "gringo" o "gallego", proferidos en un sentido agravante, habrían partido de expresiones xenófobas por parte de miembros de la elite argentina, atemorizados ante el creciente torrente de inmigrantes.

${ }^{17}$ Escrito de manera conjunta por Ramos Mejía e Ingenieros, fue publicado en los $A P C$, vol. VIII (517-547) en el año 1909. 
cológico que acompaña al instinto de reproducción - como un hecho patológico (542).

Ahora bien, en el marco de esta investigación refieren de manera explícita sobre el modo en que su disciplina irrumpe en la consideración de un conflicto que no sería tradicionalmente propio, "Filósofos y poetas podrán, acaso, sonreír ante esta inesperada invasión de sus dominios por la medicina legal" (517). Una vez concluidos diagnóstico y peritaje, y cuando los saberes científicos y jurídicos ya no ofrecen mayores interpretaciones para plantear sobre el caso de X. N., señalan:

Fuera de la medicina legal se ha disertado ampliamente sobre la posibilidad de considerar a la pasión como un estado patológico. Ovidio y Petrarca sabían que el hombre enamorado actúa distintamente del hombre indiferente. Stendhal lo repitió [...] Las variaciones que el amor hace sufrir a la personalidad humana son las mismas que ella experimenta bajo la influencia de los demás sentimientos, pasiones y emociones. La piedad, la avaricia, y el miedo; la tristeza, el juego y la cólera [...] Todas esas manifestaciones de la vida afectiva, en sus formas intensas y críticas, ponen a la personalidad en situación anormal y pueden dar tema al filósofo o al artista para considerarlas como estados patológicos del "yo", en cuanto perturban el juicio, polarizan el razonamiento o desvían la conducta con sus normas habituales. Pero el derecho civil se mantiene ajeno a tan interesantes torneos del ingenio humano (542-543).

De este modo, sobre el final del artículo, los locutores concluyen la investigación ofreciendo otro punto de vista sobre la concepción patológica de las pasiones, objeto privilegiado en la historia de las letras. La literatura es invocada, en este caso, como material de apoyo frente a ciertos límites que las ciencias criminológicas presentan. La mirada médico-legal da cuenta del modo en que la creación artística ha concebido a las pasiones y emociones como determinantes de una anormalidad en la personalidad del sujeto. Antes de concluir, los locutores remarcan la idea de que sus campos disciplinares no han penetrado en reflexiones concernientes a "los estados del yo" en situación de pasión-patológica, pero enfatizan, no obstante, que tales estudios implicarían "tan interesantes torneos del ingenio humano", desafíos intelectuales propios de filósofos y poetas. ${ }^{18}$

${ }^{18}$ Vale destacar, como otra manifestación por el interés escriturario, que también fueron publicadas en los APC dos poesías escritas por pacientes psiquiátricos: "Intros- 


\section{Los recursos de la narración científica}

Este vínculo forjado entre ciencias y letras que caracterizó el desarrollo de los estudios clínicos tanto de Ramos Mejía como de Ingenieros, no se limitó al recurso de la cita literaria para ejemplificar o argumentar, ni a la incorporación de nuevas perspectivas que, más allá de la clínica, pudieran abordar el fenómeno patológico. Así como es posible desmontar en estos documentos toda una red de lecturas de ficción que atraviesa desde los clásicos de la Antigüedad hasta los poetas simbolistas franceses del siglo XIX, también se pueden detectar ciertas formas narrativas que, en la formulación de los casos clínicos, dan cuenta de una escritura atenta a los recursos literarios. Si se ha concebido a la medicina como una práctica basada en la narración, y al registro del médico propio de los casos y de las historias clínicas como una operación discursiva en la cual se narra la historia de un paciente (Salto, "De las escenas de colegio a las escenas de hospital", 120), me propongo analizar la articulación de los procedimientos narrativos de Ingenieros y Ramos Mejía en el marco de la configuración de un ethos médico-letrado.

\section{Los personajes de los informes criminológicos}

Los sujetos cuya historia clínica era examinada y analizada en los estudios de casos que tuvieron lugar en la tesis de Ingenieros y en numerosas investigaciones de Ramos Mejía (entre las de muchos otros médicos del período) solían denominarse bajo el rótulo de una "doble equis" o "doble ene" (X.X., N.N.), o bien bajo dos iniciales (D.P., S.S., M.S., P.Q.), o bien a partir de un seudónimo (El ganzo, El chilenito). No obstante, también fueron registrados no pocos exponentes de casos médico-criminológicos en los que, por el carácter perturbador o extravagante de los hechos - rasgo que despertaría el interés de la prensa general y especializada - , el sujeto en cuestión resultaba denominado

pección analítica de su estado mental por un poeta neurasténico. Desequilibrio" (vol. I, 689-690) y "Poema erótico escrito por un demente precoz" (vol. viI, 598), en los años 1902 y 1908 , respectivamente. 
con su nombre y apellido (Alejandro Puglia, por ejemplo).$^{19}$ No fueron poco frecuentes, tampoco, los casos en que además de identificar a los sujetos con su nombre, se les antepusiera un epíteto con el fin de caracterizar algún matiz de su "predisposición criminal". De este modo, se volvieron conocidos y sometidos a debate casos como los de "el clérigo asesino Pedro Castro Rodríguez", ${ }^{20}$ "el parricida José Vivado", ${ }^{21} \mathrm{o}$ "el envenenador Luis Castruccio", difundidos en géneros discursivos científicos y periodísticos en los cuales los pacientes-delincuentes comenzaron a asumir cierto estatuto cercano al de complejos, oscuros y controversiales personajes literarios.

Este último, un inmigrante italiano arribado al país en 1878 que se constituyó como uno de los "personajes célebres" entre los anales criminalísticos argentinos, fue analizado en la serie de observaciones que Ingenieros compiló en su estudio sobre "Los errores judiciales en los alienados delincuentes" en 1909 (APC vol. VIII, 5-72). Una vez asentado en la ciudad de La Plata, capital de la provincia de Buenos Aires, Castruccio ideó el modo de resolver su situación económica mediante el cobro de una póliza de seguros. Para ello, a través de la publicación de un aviso en el que ofrecía empleo a un "mucamo", logró que Alberto Bouchot Constantín no sólo accediera al trabajo sino que también firmara los distintos documentos que Castruccio le presentaba. Éste hizo

${ }^{19}$ Puglia, el célebre criminal de origen italiano, se constituyó, para Ingenieros, en "uno de los casos más complejos e interesantes con que hemos tropezados en nuestras investigaciones de psiquiatría criminal, desde la fundación del Instituto de Criminología en Penitenciaría de Buenos Aires" (APC vol. viI, 3).

${ }^{20}$ En 1888, el presbítero Castro Rodríguez, sacerdote de Olavarría (Buenos Aires), asesinaba a su mujer (Rufina Padín) con quien se había casado en el marco del Iglesia Metodista, y a su hija (Petrona María Castro), a causa de la supuesta infidelidad cometida por aquella (Estudios clínicos de enfermedades nerviosas y mentales, 208).

${ }^{21}$ Se trata del inmigrante italiano que en 1877 asesinó a su padre. El estado mental de Vivado despertó diversas investigaciones médicas en las que intervinieron los médicos Lucio Meléndez ("Refutación clínico-psicológica del informe legal expandido por el Consejo de Higiene Pública sobre el estado mental del parricida José Vivado", 3) y Pablo Santillán ("Informe médico legal en la causa seguida al parricida José Vivado", Anales del Círculo Médico II, 163). Hugo Vezzetti (La locura en la Argentina, 145153) ha analizado la polémica entre ambos documentos concernientes al estado médico psiquiátrico de Vivado. Ramos Mejía (Estudios Clínicos de enfermedades nerviosas y mentales, 124) también refiere el caso del parricida Vivado para explicar la epilepsia de cráneo inválido. 
pasar a Constantín como empleado y cuñado suyo, y una vez que logró asegurarlo, dio comienzo a la ejecución de su crimen.

Ingenieros afirma que "la descripción fidedigna de las tentativas de cloroformización de Castruccio es una página criminal digna de tentar la pluma del novelista" (46) y, de manera similar, el enunciador que construye para dar cuenta del caso asume los recursos propios de este tipo de narrador:

Castruccio, protegido por la obscuridad de la noche se acercaba a la cama de su víctima cuando ésta ya dormía, aproximaba lentamente a su boca un trapo humedecido en cloroformo y la dejaba respirar un momento: en seguida, embebía más el trapo y volvía a aproximarlo, cuidando evitar todo contacto que pudiera despertar a la víctima, cuya expresión fisonómica observaba con curiosidad siniestra. Poco a poco aumentaba la dosis del anestésico: Constantín se agitaba un poco y despertaba; entonces Castruccio se agazapaba en las tinieblas, conteniendo el aliento para que no se sospechara su presencia. Luego, cuando el rumor de la respiración profunda le avisaba que Constantín dormía de nuevo, recomenzaba la tarea protegido por la sombra: con la perseverancia de un artista que modela el barro indócil hasta arrancarle una forma que traduzca fielmente la concepción de su ingenio. Así trabajó varias noches, firme en su tarea, decidido a cumplir el crimen que comenzaba a obsesionarlo, exaltando su amor propio degenerativo y trágico (46).

En este sentido, la creación del suspenso a partir de un ritmo pausado y aletargado, articulado en el pretérito imperfecto en que se desarrolla el relato, la construcción de juegos de imágenes entre luces y sombras, las analogías entre el ingenio del criminal y la invención artística, la introducción en las emociones del protagonista y en su obsesión por la víctima, entre otras estrategias narrativas, dan cuenta de otro tipo de manifestación escrituraria del locutor, vinculada a la sensibilidad del creador del cuento policial. En la construcción de estos personajes desequilibrados resuenan otras lecturas de Ingenieros, como las que describían a los criminales voluptuosos de los cuentos de terror de Poe, a quienes Ingenieros menciona para comparar estos procederes con distintos tipos de conductas que se alejan de los criterios de lo normal (La simulación de la locura, 290).

Un procedimiento similar ocurre en la construcción del informe médico-legal concerniente a la familia Lobato que Ramos Mejía publica 
bajo el título de "Locura comunicada" en su compilación Estudios clínicos de enfermedades nerviosas y mentales. El informe da cuenta del estado mental de Ángela L. de Lobato y de sus hijos Nieves, Cesáreo, Micaela y Juan Lobato, todos implicados en el homicidio de un menor de edad, en la Provincia de Buenos Aires, hacia el año $1881 .{ }^{22}$ Luego de describir la serie de degeneraciones físicas y psiquiátricas que acechaban a la familia desde generaciones anteriores, el narrador del informe relata el modo en que Nieves "la actora principal de este drama" (190), persuade a sus hermanos y los conduce al asesinato del niño. Sobre un diagnóstico de enajenación mental generalizada, Nieves es presentada como, "la heroína en este drama oscuro e interesante bajo su punto de vista" (190) en tanto que su madre y hermanos resultan los personajes secundarios de la obra que "actúan y se doblegan mansamente" a partir de la "imperiosa influencia" (202) de aquella.

De este modo, las elaboraciones de Ingenieros y de Ramos Mejía resultan paradigmáticas entre aquellos casos e informes médico-legales que hacia 1870 empezaron a poblar las publicaciones especializadas y que fueron señalados como "trabajos literarios" dotados de una trama novelesca (Salto, "De las escenas de colegio a las escenas de hospital", 113). ${ }^{23}$ En sus escritos, además, los recursos narrativos se conjugan a los señalamientos autorreferenciales del género que se ocupan de anticipar los casos como dignas páginas del novelista policial o del oscuro dramaturgo; otra dimensión propia de la conformación de una imagen de médicoletrado.

\section{La creatividad terminológica en la lección de cátedra}

Otro fenómeno que también definió la discursividad médica de Ramos Mejía fue la articulación de una terminología novedosa, cuya originalidad misma resulta mencionada en sus elaboraciones. A lo largo de sus "Lecciones" un yo-enunciador, se hace constantemente presente con

${ }^{22}$ Los hechos ocurrieron en el Departamento de 25 de mayo (Provincia de Buenos Aires) en abril de 1881.

${ }^{23}$ Graciela Salto considera que el informe médico legal, a diferencia del caso, recibe su impulso primario de una institución, mientras que el caso parte del afán de divulgación de una experiencia surgida de un anecdotario personal (120-121). 
el fin de señalar los procesos de invención léxico-científica capaces de configurar el objeto de estudio. En la "Lección I: sobre los delirios simuladores" proliferan enunciados como: "me ha sugerido la creación de esta denominación de delirios simuladores" (56); "estos que yo llamo delirios simuladores" (68), "Por eso les he llamado delirios simuladores" (75) que procuran enfatizar el proceso de acuñación de los nuevos términos. Este yo se opone a un nosotros que, aunque en otros momentos lo incluye, representa a la comunidad médico-académica que comúnmente estudia "delirios conocidos por su etiología [...] que llamamos generalmente orgánicos" (56). Además, en ciertos momentos de esta Lección el enunciador invoca de manera manifiesta a sus alocutarios, para referirse a estos procesos de creación terminológica, mediante expresiones como "permitidme el neologismo" (82). ${ }^{24}$

La invención de neologismos como procedimiento en la enunciación médico-pedagógica se repetirá en la "Lección v: Los epilépticos bromiómanos", en la que no sólo explica "etimológicamente" el nuevo término implementado - "los bromiomános son, como lo indica la sencilla etimología de la palabra, los que tienen la pasión, más bien que la manía de tomar bromuro de potasio" (143) - sino que con el correr de las páginas lo reivindica, señalando que se trata ya de un "neologismo consagrado" (148). Estas operaciones expondrán su continuidad, ya por fuera de estas lecciones, en el ensayo de Ramos Mejía sobre Los simuladores del talento (1904), en cuyas páginas el yo-enunciador explicita su actitud frente a este recurso discursivo - "Yo soy tan aficionado al neologismo y al terminacho expresivo" (145) - así como establece referencias similares respecto a otros recursos — "si me dejáis pasar lo exótico de la imagen" (22) - manifestaciones propia del ethos dicho (en tanto se trata de evocaciones de su propia enunciación por parte del enunciador - Maingueneau, "Problèmes d'ethos", 64-66-) que confirma la imagen de creatividad y sensibilidad frente al lenguaje, propia del locutor.

${ }^{24}$ Entiendo por alocutario al destinatario propiamente dicho (que puede ser singular o plural, nominal, anónimo, real o ficticio) y que se define por el hecho de ser explícitamente considerado por el emisor, lo que atestigua el empleo del pronombre en segunda persona y/o dirección de la mirada como compañero en la relación de alocución (Kerbrat-Orecchionni, La enunciación. De la subjetividad en el lenguaje, 32). 


\section{Los médicos literatos}

En este marco de enseñanza de la medicina no llamará la atención que sea Francisco Sicardi (1856-1927), el médico argentino que se presente como primer homenajeado en la sección "Biografías" de la Revista del Centro de Estudiantes de Medicina (núm. 94, 25-28). Sicardi, además de médico, profesor de clínica médica y director del Hospital San Roque, resultó reivindicado como escritor de una serie de ficciones de raigambre naturalista. ${ }^{25}$

Algunos años antes, en 1903, los Archivos de Psiquiatría y Criminología habían presentado, bajo la discontinua sección "Impresiones médico-literarias" el relato de Sicardi sobre "La vida del delito y la prostitución" (vol. II, 11-21) que exponía las visiones ofrecidas por el paisaje humano en una serie de recorridos realizados por las distintas cárceles de de Buenos Aires. "Más que personas [...] parecen espectros con el rostro y el cuerpo escuálido" (11), señala un enunciador que, a su vez afirma, "yo puedo contar muchas historias" (18), tales como las de un quinceañero rubio y de ojos azules siempre rodeado de amigos enfermos (13), un grupo de mujeres sifilíticas que han diseminado sus gérmenes mortales por toda la ciudad (15), un hijo de los bulevares, con sus miembros contraídos, y atónito de hambre (12), cada uno se integra a una verdadera galería de personajes, protagonistas de embriones narrativos de historias truncas, o sólo esbozadas en breves párrafos. A ellos se suman "borrachos e idiotas", "hermanos del delito, rameras, ladrones, rufianes, falsarios, adúlteros, arteros y asesinos" (21). El enunciador se presenta entonces como un compilador y a la vez difusor de todos estos personajes marginales que "narran los poemas del vicio", "describen los descensos de las juveniles energías" o "cuentan facinerosas historias de noches lóbregas" (11). El hecho de que sea Sicardi, entre las distintas eminencias de la medicina nacional, el que inaugure esta sección de la RCEM, permite corroborar el perfil de médico que, con-

${ }^{25}$ Aunque Sicardi atravesó los distintos géneros literarios (cuentos, poesías, teatro, ensayos), fue recordado, sobre todo, por los cinco volúmenes de su Libro Extraño, que publicó entre 1894 y 1902, en el que narraba las desventuras de una familia de psicópatas, marcados por las herencias de las megalomanías y las erotomanías. 
figurado en la articulación entre las ciencias y las letras, era presentado como referente para los estudiantes de medicina del período.

\section{Notas finales}

Con una marcada representación de la responsabilidad en la tarea educativa, Ramos Mejía imaginó la carrera de medicina como un ámbito de formación integral en el que, sin limitarse a los conocimientos clínicos, el alumno fuera convocado y animado a las prácticas de la lectura y de la escritura. Inició una cruzada por construir un auditorio culto, que superara los conocimientos clínicos en sus distintas especialidades. Desde el "Discurso en el Círculo Médico" (1891) apostó a inculcar, en alumnos y colegas, el hábito por desarrollar un saber letrado, desafío que fue prolongado por la RCEM en la primera década del siglo Xx. Desde su perspectiva, el ejercicio de la medicina no resultaba eficaz, si no era acompañado por la práctica de una buena retórica, por lo que se procuró crear una nueva palabra médica basada en ciertos principios: claridad, orden, corrección, solidez y elegancia. La lectura de obras literarias, de este modo, le otorgarían al médico las capacidades de una oratoria necesaria para la elaboración de explicaciones precisas y elocuentes, requisito de la discursividad médica.

José Ingenieros, en tanto, no sólo desplegó sus prolíferos y exhaustivos conocimientos literarios en sus apuntes científicos, sino que tomó de este saber los casos ejemplares para ilustrar los cuadros patológicos que exponía, técnica pedagógica que ya era utilizada en Europa para la enseñanza de la medicina. Los Archivos de Psiquiatría y Criminología, publicación por él dirigida, así como la Revista del Centro de Estudiantes de Medicina, apuntaron a la conformación de un auditorio capaz de reflexionar sobre su práctica a partir de la manifestación literaria. La conformación de un ethos letrado en la producción médico-académica de ambas figuras, puede leerse también a partir de un trabajo de escritura reflexivo, atento al uso del vocabulario y a la articulación de neologismos en el marco de las lecciones, pero sobre todo, a la temporalidad narrativa, la dramatización de los personajes y la construcción del suspenso en el marco de los casos clínicos-criminológicos producidos. 
En fin, al analizar los saberes y valores que intentaron ser inculcados entre los futuros médicos argentinos, este trabajo ha indagado un vínculo poco explorado por los estudios historiográficos y educacionales de la medicina nacional. La enseñanza y la investigación en el área resultaron, durante estas décadas, atravesadas por distintos objetos e intereses del ámbito literario. Tal imbricación definió un momento de la medicina argentina a partir de algunas voces formadoras, sensibles e instruidas en el saber letrado. Considero que la observación de continuidades, desplazamiento o exclusiones de tales intereses en la educación médica nacional, en períodos posteriores, puede ser indagada con el fin de reflexionar sobre qué modelos de médicos se han formado en nuestro país, y en base a qué conocimientos han sido adoctrinados.

\section{REFERENCIAS}

Amossy, Ruth, Images de soi dans le discours. La construction de l'ethos, Paris, Delachaux et Niestlé, 1999.

Amossy, Ruth, L'argumentation dans le discours, Paris, Nathan, 2000.

Amossy, Ruth, "Nueva retórica y lingüística del discurso", en Koren, R. Y Amossy, R. (eds.), Aprés Perelman. L'argumentation dans les sciences du langage, Paris, L'Harmatan, 2002, 153-172, trad. Nicolás Bermúdez, Buenos Aires, Facultad de Filosofía y Letras, 2007, 1-13.

Bertoni, Lilia Ana, "Soldados, gimnastas y escolares. La escuela y la formación de la nacionalidad a fines del siglo XIX", Boletín del Instituto de Historia Argentina y Americana Dr. Emilio Ravignani 13, 1996, 35-57.

Biagini, Hugo, "Redes estudiantiles en el Cono Sur (1900-1925)", Movimientos Estudiantiles en la Historia de América Latina III, 2006, 279-296.

Buchbinder, Pablo, Historia de las Universidades Argentinas, Buenos Aires, Sudamericana, 2005.

Сівотті, Ema, "Del habitante al ciudadano. La cuestión del inmigrante", en Nueva Historia Argentina. El progreso, la modernización y sus límites (18801916), Mirta Lobato (dir.), Buenos Aires, Sudamericana, 2000, 365-408.

GonZÁlez LEANDRI, Ricardo, “Académicos, doctores y aspirantes. La profesión médica y la reforma universitaria: Buenos Aires 1871-1876", Entrepasados, IV , 12, 1997, 31-54.

Ingenieros, José, La simulación de la locura [1900], Buenos Aires, L. J. Rosso, 1918 . 
Ingenieros, José, "Introducción a Los Degenerados y Criminales en la obra de Zola de Enrique Ferri”, Archivos de Psiquiatría y Criminología I, I902, 622-670.

Ingenieros, José, La simulación en la lucha por la vida [1903], Buenos Aires, Meridion, 1954.

Ingenieros, José, "La psicología en el arte", Archivos de Psiquiatría y Criminología II, 1903, 27-40.

Ingenieros, José, "Locura, Simulación y Criminalidad", Archivos de Psiquiatría y Criminología VII, 1908, 3-26.

INGENIEROS, José, "Los errores judiciales en los alienados delincuentes", $R e$ vista de la Sociedad Médica Argentina XVII, I909, 5-72.

Ingenieros, José, "Patología de las Funciones Psicosexuales Nueva clasificación genética”, Archivos de Psiquiatría y Criminología Ix, I9Io, 1-80.

Ingenieros, José, La locura en la Argentina, Buenos Aires, Cooperativa Editorial Limitada, 1920.

Kerbrat-Orecchioni, Catherine, L'Énonciation - De la subjectivité dans le langage [1980], trad. Gladys Anfora y Emma Gregores, Buenos Aires, Hachette, 1986.

Loudet, Osvaldo, "La moral de la ciencia", Revista del Centro de Estudiantes de Medicina y del Círculo Médico 1, 1909, 33-40.

Maingueneau, Dominique, "Problèmes d'ethos", Pratiques 113/114, 2002, 55-67.

Maingueneau, Dominique, Doze conceitos em análise do discurso, São Paulo, Parábola Editorial, 2010.

Pi y Molist, Emilio, "Primores del Don Quijote en el concepto médico-psicológico", Archivos de Psiquiatría y Criminología XI, 1912, 611-616.

Ponce, Aníbal, "Para una historia de Ingenieros", en José Ingenieros. Obras Completas, Tomo I, Buenos Aires, J. L. Rosso, 1939.

Ramos Mejía, José María, Estudios Clínicos de enfermedades nerviosas y mentales, Buenos Aires, Félix Lajouane, I893.

Ramos Mejía, José María, Los simuladores del talento [1904], Buenos Aires, Tor, 1955.

Ramos Mejía, José María y José Ingenieros, "Amor e incapacidad civil" Archivos de Psiquiatría y Criminología vIII, 1909, 517-547.

Rodríguez Morini, Antonio, "La locura de Don Quijote", Archivos de Psiquiatría y Criminología v, 1906, 763-767.

Romero, José Luis, El desarrollo de las ideas en la sociedad argentina del siglo XX, Buenos Aires, Nuevo País, 1987.

Rovaletti, Lucrecia, "Panorama psicológico", en El movimiento positivista argentino, Hugo Biagini (comp.), Buenos Aires, Belgrano, 1985, 241-320. 
SALto, Graciela, "De las escenas de colegio a las escenas de hospital: la trama higienista en narraciones, anécdotas y casos", en Higienismo, Educación y Discurso en Argentina (1870-1940), María Silvia Di Liscia y Graciela Salto (eds.), La Pampa, Universidad de La Pampa, 2004, 113-135.

SiCARDI, Francisco, "La vida del delito y la prostitución", Archivos de Psiquiatría y Criminología II, 1903, 11-21.

TABORDA, Héctor, "Carta a mis lectores", Revista del Centro Estudiantes de Medicina 83, I908, 1-2.

TABORDA, Héctor, "Carta de despedida a mis lectores", Revista del Centro Estudiantes de Medicina 94, 1908, 1-2.

Veyga, Francisco de, "Vida y trabajos del Dr. José María Ramos Mejía", Semana Médica 45, 1939, 5-31.

Vezzetti, Hugo, "La locura y el delito. Un análisis del discurso criminológico en la Argentina del novecientos", en El discurso jurídico. Perspectivas y otros abordajes epistemológicos, Buenos Aires, Hachette, 1982, 233-257.

Vezzeti, Hugo, La locura en la Argentina, Buenos Aires, Paidós, 1985. 